Department of Health, along with professional bodies, formulate guidelines for the introduction of genetic screening programmes.

This report will do much to facilitate the extension of screening programmes in Britain, to allay the fears of the public about such screening, and to protect individuals from violations of their rights. It is a very solid piece of work, and I recommend it highly to all interested parties.

ROGER CRISP St Anne's College, Oxford.

\section{Standard of care - the law of American bioethics}

\author{
George J Annas, New York and \\ Oxford, Oxford University Press, \\ 1993, 291 pages, $£ 19.50$
}

Here we have another elegant, thought-provoking volume from the prolific Professor Annas. Like the others, it is almost a collection of essays, in this case divided up to cover three discrete themes, with an overarching theme which allows him a forceful conclusion about the way we should think now. For Annas is one of the most powerful proponents within the United States of a medical ethics that goes beyond the purely legal. As a lawyer himself, he sees bioethical thinking as overly law-based. He sees, too, the practice of defensive medicine on the increase, of interventions performed in order not to get sued, rather than for the possible benefit of the patient, and he states categorically that such interventions are unethical.

But in this volume, more than in previous ones, he calls for a tangible change. He suggests - and we have to remember that he is first and foremost a lawyer himself - that at least one semester of the third year of law school be used for the study of health law. That would, in his view, change the way lawyers think, and reform their practice in health-care cases.

But he also argues that the United States is a country of disparate peoples of different traditions, religions and values, held together by law. In his view, an intensive study of health law would encourage law students to think creatively and humanistically about all the troubling issues of informed consent, abortion, the right to die, and organ transplantation, and, through them, society itself would be influenced.

It is hard to know whether he is right. Undoubtedly, health law would be an important part of legal studies and would sharpen up the way bioethicists think about issues. But, if Annas is right in thinking that too many bioethicists think in terms of what is legal rather than in terms of what is right, should there not be a course of moral philosophy instead of law, aimed at getting students thinking about what people's rights ought to be in relation to a variety of issues, such as the right not to have organs harvested from a suddenly dead relative? Lawyers might have a lot to contribute, but my favoured option, after reading Annas's superbly elegant account of the questions set by the Supreme Court dramas and by private cases, discussing what standards of care ought to be, is to get medical students thinking harder about ethics. That might discourage defensive medicine, encourage discussing options with patients, and help doctors recognise where some matters are so personal - such as abortion - that it is essential that individuals be allowed to choose what treatments they want, including treatments disapproved of by some practitioners, politicians or other members of society.

But Annas makes a brave case for training lawyers, and he might be right. This is a fascinating book, with all its case-studies. The only quibble is over the indexing and proof-reading, which leave much to be desired. Ronald Dworkin, for instance, gets indexed with two references. But, in the text, one is a Ronald, one a Roger. It would help to be clear about this (my guess is both Ronald), and to have footnotes rather than end-notes, or at least chapter titles for the endnotes so the readers can find their way about. But this is minor carping in the case of an otherwise fine, readable, funny, provocative and challenging volume.

RABBI JULIA NEUBERGER Chair, Camden and Islington Community Health Services NHS Trust,

36 Orlando Road, London SW4 OIF.

\section{Children's consent to surgery}

Priscilla Alderson, Buckingham, Open University Press, 1993, 212 pages, hc $£ 37.50$, pb $£ 12.99$.
Discussions on consent to surgery in children have usually centred on who gives consent when the child has limited understanding and judgement, and at what stage a child has the maturity to make, or participate in making, decisions. Most difficulties surround procedures or surgical operations where the clinical issues are not clear-cut, or where results are uncertain.

This thought-provoking book considers the involvement of children themselves in decision-making about the surgery which it is proposed they should undergo. It assesses the ability of children to make informed and wise judgements about their own surgery, and also provides a lot of insights into the workings of hospitals, and into the strengths and shortcomings of hospital services for children. It also reflects on children's place in society, and the importance of children's rights in the issues surrounding consent to surgery.

The book is based on a research project carried out by the author and her co-researcher Jill Siddle, in which 120 patients aged 8-15 years were interviewed two or more times. Also interviewed were those adults parents and health care professionals who were caring for them around the time of surgery. All the patients involved in the study were having orthopaedic treatment. This forms a significant part of non-emergency major surgery carried out in the 8-15 year-old age group, and often involves multiple procedures and prolonged stays in hospital. Many of the children interviewed had already had previous experience of surgery.

Most of the children interviewed had a good understanding of their problems, and hoped that surgery would improve their condition. The main improvements the children hoped for were improved mobility, prevention of disability worsening, and pain relief. On the whole parents' hopes were similar. Surgical outcomes in many of the conditions involved in the study - scoliosis, leg-lengthening, or correcting malformations and deformities - are not always certain, but most children and parents were willing for surgery to take place.

As a group the children nearly all wanted to understand about the treatment proposed, and be involved in the decisions, and parents and professionals supported this in principle. More difficult to assess was children's competence to decide, based on understanding the treatment 